\title{
Tooth 19
}

National Cancer Institute

\section{Source}

National Cancer Institute. Tooth 19. NCI Thesaurus. Code C60728.

The first, permanent, six-year molar of the lower left arch as defined by the Universal tooth numbering system. 